\title{
Integrated production systems for glasshouse horticulture
}

\author{
G.W.H. WELLES
}

Glasshouse Crops Research Station, P.O. Box 8, NL 2670 AA Naaldwijk, Netherlands

Received 13 December 1991; accepted 9 April 1992

\begin{abstract}
Current glasshouse horticulture in the Netherlands is based on high inputs of energy, fertilizers and pesticides, with serious environmental effects. Consequently, it has to face a restrictive governmental policy and changing consumer attitudes towards the quality of products in relation to the production process. Integrated production systems with minimum inputs are described, e.g. efficient use of energy, nutrient and pesticides, with as a consequence, minimum emissions. These systems will be introduced after tests with prototype systems for pilot crops of major crop groups.
\end{abstract}

Keywords: production system, fertilizers, energy, pesticides, waste, integrated production system, production process, pilot crop, product quality, management, consumer attitude, labour conditions.

\section{Introduction}

Dutch horticulture under glass is aimed at high production levels and excellent product quality. It requires relatively high inputs of fertilizers and energy for optimal control of growth and product quality. In order to minimize risks, it is still based on high input of pesticides (Table 1), despite increased application of biological control

Table 1. Estimated input of pesticides, fertilizers and energy in the various horticultural sectors in the Netherlands.

\begin{tabular}{|c|c|c|c|c|}
\hline $\begin{array}{l}\text { Horticultural } \\
\text { sector }\end{array}$ & $\begin{array}{l}\text { Area } \\
\text { (ha) }\end{array}$ & $\begin{array}{l}\text { Pesticides } \\
\left(\mathrm{kg} \text { a.i. } \mathrm{ha}^{-1} \mathrm{yr}^{-1}\right)\end{array}$ & $\begin{array}{l}\text { Fertilizers* } \\
\left(\mathrm{kg} \mathrm{N}, \mathrm{P} \text { and } \mathrm{K} \mathrm{yr}^{-1}\right)\end{array}$ & $\begin{array}{l}\text { Energy* } \\
\left(10{\left.\mathrm{TJ} \mathrm{yr}^{-1}\right)}^{-1}\right.\end{array}$ \\
\hline \multicolumn{5}{|l|}{ Indoors } \\
\hline floriculture & 5100 & 75 & 3000 & \multirow{2}{*}{$\begin{array}{l}104000 \\
\text { growing }\end{array}$} \\
\hline vegetable & 4400 & 35 & 2500 & \\
\hline $\begin{array}{l}\text { Outdoors } \\
\text { vegetable } \\
\text { growing }\end{array}$ & 42800 & 30 & 30 & \multirow{4}{*}{6000} \\
\hline fruit growing & 24700 & 20 & 160 & \\
\hline arboriculture & 9600 & 75 & 390 & \\
\hline bulb growing & 16700 & 125 & 370 & \\
\hline
\end{tabular}

* Figures are rough estimates and are presented as indications for input.' 
methods. Spider mite, thrips, aphids and whitefly are controlled successfully in practice by means of biological methods, whereas all fungi are still controlled with pesticides.

Artificial substrates are increasingly used (more than $80 \%$ of the acreage of fruit vegetables) and result in substantial waste streams, such as substrates and plastics. As a consequence, consumers increasingly consider glasshouse horticulture as an industrial activity rather than a natural production process, affecting product quality, such as taste. This increasing public concern is an important starting point for policy plans of the Dutch government aimed at sustainable, safe and competitive production systems. This paper presents the research efforts to develop, test and introduce multipurpose or integrated systems for horticulture under glass.

\section{Objectives, materials and methods}

Following a general method for definition, elaboration and evaluation of integrated farming systems (Vereijken, 1992), three major objectives of integrated glasshouse systems can be identified, along with the appropriate materials and methods to achieve them (Table 2). Especially the objectives of environment, health and wellbeing require innovation of the production systems. Research into this field should especially consider consumers attitudes towards internal quality aspects of the product, such as residues of chemical pesticides, nitrate content and taste.

The government has formulated aims for three main issues of environmental management, i.e. nutrients, pesticides and energy, based on the National Environmental Policy Plan (Anomymous, 1990) and the Multi-year Crop Protection Plan (Anonymous, 1991, Table 3). To achieve the final aim of $100 \%$ recirculation of nutrients by the year 2000 is an enormous task. It may be expected that this aim can not be reached when growing in normal soil, because of uncontrolled emission of nutrients. With soilless culture systems, the final aim may be reached, provided a high quality of the irrigation water. At the moment only $45 \%$ of the total glasshouse area is under soilless culture. Nevertheless, these objectives are considered binding, which puts a heavy responsibility on the shoulders of the glasshouse industry and its supporting research institutes, demanding a comprehensive, interdisciplinary and practical approach.

Table 2. Objectives, materials and methods of integrated glasshouse production systems.

Objectives

1 Basic income and maximum profit

2 Minimum pollution of soil, water and air

3 Maximum contribution to health and wellbeing of producers and consumers
Materials and methods

Cost efficient quality production

Minimum emission of nutrients, pesticides, waste, $\mathrm{CO}_{2}$ (and other gaseous pollutants) and light

Healthy labour conditions; products with minimum residues of harmful compounds and high consumption value 
Table 3. Short. and long-term environmental aims of the glasshouse sector.

\begin{tabular}{|c|c|c|c|}
\hline Issue & Type of crop & $\begin{array}{l}\text { Short-term aims } \\
\text { (year 1994) }\end{array}$ & $\begin{array}{l}\text { Long-term aims } \\
\text { (year 2000) }\end{array}$ \\
\hline \multirow[t]{2}{*}{ Nutrients } & $\begin{array}{l}\text { vegetables and } \\
\text { pot plants }\end{array}$ & $\begin{array}{l}80 \% \text { soilles culture of } \\
\text { which } 30 \% \text { with recircu- } \\
\text { lation of nutrients }\end{array}$ & $\begin{array}{l}100 \% \\
100 \%\end{array}$ \\
\hline & cut flowers & $\begin{array}{l}30 \% \text { soilless culture and } \\
30 \% \text { with recirculation } \\
\text { of nutrients }\end{array}$ & $\begin{array}{l}100 \% \\
100 \%\end{array}$ \\
\hline Pesticides & overall & & $\begin{array}{l}65 \% \text { less input of active } \\
\text { ingredients, compared } \\
\text { to } 1988\end{array}$ \\
\hline Energy & overall & & $\begin{array}{l}50 \% \text { higher efficiency, } \\
\text { compared to } 1980\end{array}$ \\
\hline
\end{tabular}

\section{Development of environmentally safe production systems}

The research strategy is to develop production systems for different crop groups that meet the following conditions:

- no emission of nutrients and pesticides into soil, surface water or groundwater;

- reduction of emission of pesticides, $\mathrm{CO}_{2}$ and pollutants into the air;

- reduction of use of pesticides;

- recirculation of nutrients and substrate;

- increase of energy-efficiency;

- excellent internal and external quality of products to ensure competitiveness on the national and international markets;

- healthy labour conditions.

A first step towards integrated production systems is the development of systems with minimal emission of nutrients and pesticides.

\section{Production systems with minimal input and emission of nutrients}

Optimization of soil-based growing systems is considered not to meet the strict legal standards for phosphate and nitrogen emission in the year 2000. Therefore our research station in Naaldwijk and the Research Station for Floriculture in Aalsmeer have chosen to develop so-called soilless growing systems (Figure 1).

Three soilless systems are being developed for six traditionally soil-grown crops, based on solid substrate, ebb/flood and root spraying techniques. Interdisciplinary working groups containing agronomists, technologists and economists continuously evaluate research results and desk studies. For each of six pilot crops (radish, lettuce, chrysanthemum, carnation, freesia and alstroemeria) out of three different crop groups (Figure 2), different types of integrated production systems are to be de- 


\section{G.W.H. WELLES}

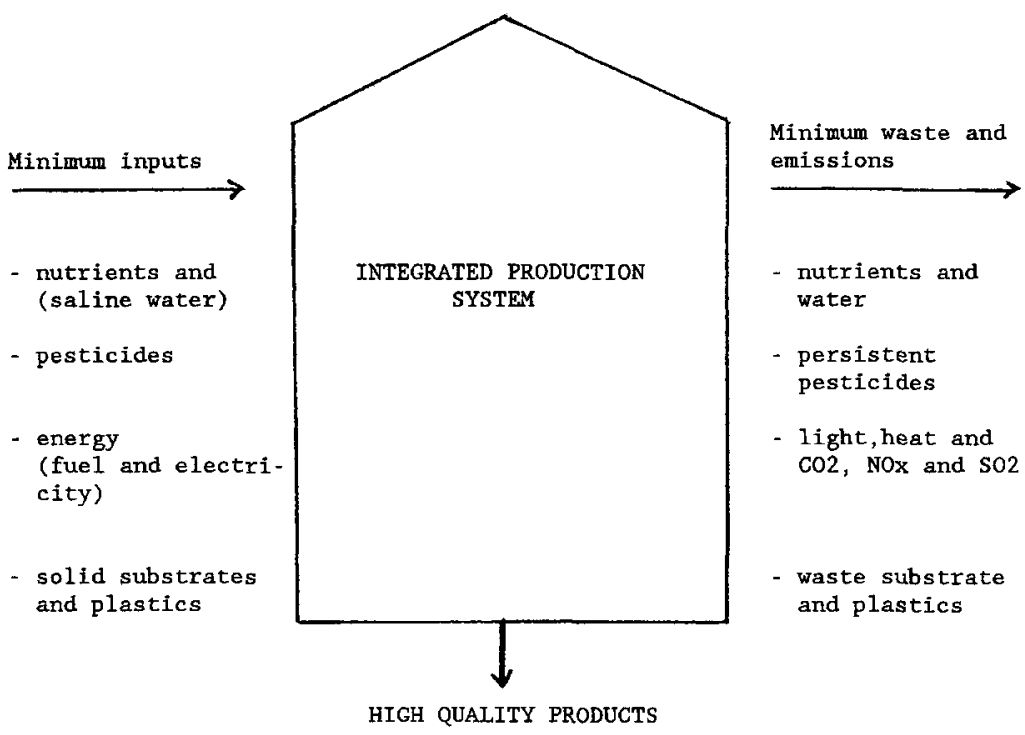

Fig. 1. Outline of an integrated production system in glasshouse horticulture based on soilless culture.

signed, tested and evaluated. Specific problems will be presented to relevant subdisciplines, e.g. (root) physiology, plant pathology and glasshouse climate. Results of the six working groups are to be evaluated regularly by a panel of experts from the horticultural industry.

A prototype of the most favourable system for each crop should be available for testing at holdings by the end of 1994 . However, an urgent problem to be solved is the salinization of the recirculating water as a result of high levels of $\mathrm{NaCl}$ in the irrigation water and low uptake of $\mathrm{Na}^{+}$by the plants. Research on removal of $\mathrm{Na}^{+}$ from the drainage water, for threshold values for crops and for increasing $\mathrm{Na}^{+}$uptake by the plants, is needed if water quality cannot be improved sufficiently at short notice.

\section{Integrated production systems with minimal input and emission of pesticides}

In agreement with the Multi-year Crop Protection Plan (Anonymous, 1991), three major aims are to be achieved:

- reduction of input of chemical pesticides;

- minimal dependence on pesticides;

- reduction of emission of pesticides in to soil, water and air.

Hygienic measures, such as healthy seeds and seedlings and clean glasshouses, provided with insect proof netting or air filters against pest and diseases, are essential for minimizing the infection pressure. A further reduction of the input of and depen- 


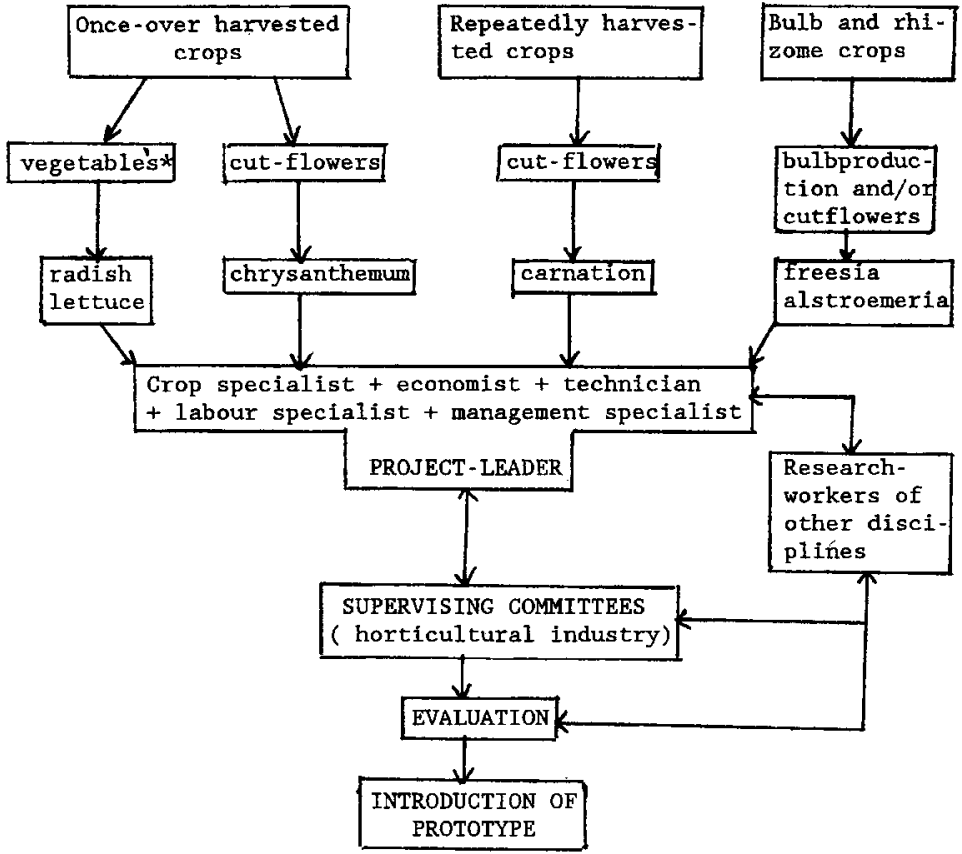

* 2 pilot crops: a leaf crop and a tuber crop.

Fig. 2. Development, evaluation and introduction of integrated production systems, based on separate working groups for pilot crops of the three crop groups.

dence on pesticides can be achieved by more biological and integrated control of insects and fungi. Building upon the successful results in practice with biological control of insects like spider mite, whitefly and leaf minor (Ramakers, 1989), control of cotton aphids and Western flower thrips in fruit vegetables, as well as biological control in leaf vegetable crops and flower crops, are currently envisaged.

Besides biological control of insects, biocontrol of fungi seems to offer perspective, as was shown for Fusarium wilt disease of carnation (Rattink, 1990) and for Fusarium foot-rot of tomato (Rattink, 1991). Improvement of application techniques of pesticides may minimize losses of the active ingredients to the environment. It is generally assumed that with conventional spraying a part of the pesticides does not reach the plants. New techniques, such as a 'spray robot', are currently envisaged, based on experiences of Van de Werken (1991) for fruit growing. Besides studies on influence of droplet size, development of better observation techniques will contribute to a more efficient way of applying pesticides. Consequently, plant pathologists and technical experts of the Research Stations Naaldwijk and Aalsmeer and the Institute of Agricultural Engineering in Wageningen are trying to minimize chemical control in roses and tomatoes as pilot crops. 


\section{G.W.H. WELLES}

Decision-making in crop protection can also be improved, as is being studied with chrysanthemum and sweet peper as pilot crops. The development of integrated information systems for these crops, supporting growers in decision-making, may contribute to a substantial reduction in the use of pesticides.

'Resistance management', aimed at optimum use of resistance factors, may limit the dependence on chemicals to a large extent, in appropriate combination with biological control and climate and plant nutrition management. Therefore, tests should become available to rapidly determine the resistance level of new varieties. In cucumber, a multi-disciplinary group is searching for varietal differences in resistance to Sphaerotheca fuliginea (mildew) which may reduce input of fungicides by more than $50 \%$ if plant nutrition and climate are well managed (Figure 3). A similar project is in preparation aimed at the combination of varietal differences in resistance to spider mite (Tetranychus urticae) and Western flower thrips (Frankliniella occidentalis) with biological control and climate management of a cucumber crop. Re-

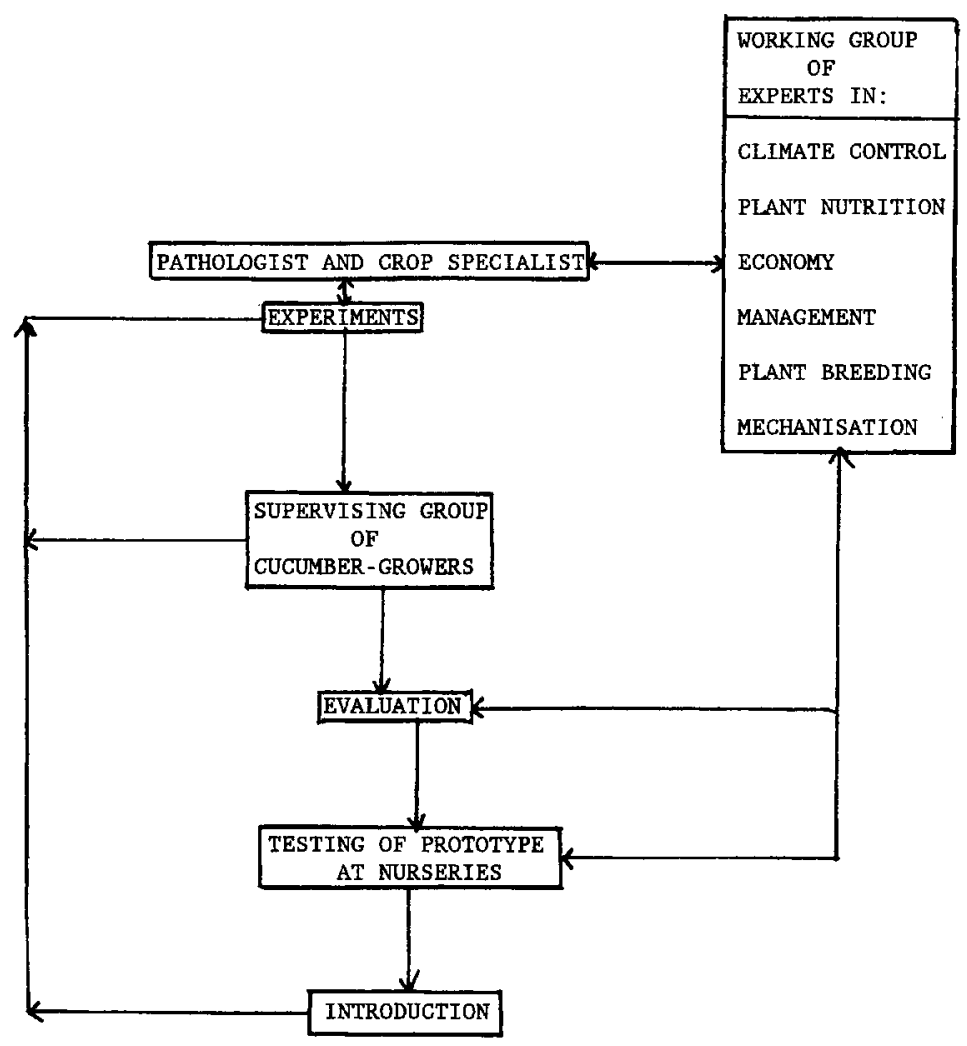

Fig. 3. Development, evaluation and introduction of an integrated control system of mildew (Sphaerotheca fuliginea) in cucumber. 
sults of both multi-disciplinary projects will support an overall integrated production system for cucumber with minimal input of pesticides.

Production systems with high energy-efficiency, low emission of $\mathrm{CO}_{2}$ and gaseous pollutants and minimal waste

Efficiency of energy use in glasshouse horticulture can be improved by lower input and higher output per square metre. Lower input of energy also reduces emission of $\mathrm{CO}_{2}$ and gaseous pollutants $\left(\mathrm{NO}_{\mathrm{x}}, \mathrm{SO}_{2}\right.$, etc.), as a result of the burning of natural gas. More knowledge on optimal use of technical facilities in and around the glasshouse (screens, ventilation, heating systems, including heat and power co-generation and clean gas burners) and on optimal control of the glasshouse climate is essential to attain these goals.

Optimization of the glasshouse climate requires better distribution of temperature and humidity, as was demonstrated by Bakker \& Van Holsteyn (1989). In cooperative research, the physical and biological effects of different patterns are being studied. Our research station (the Institue of Agricultural Engineering), the Centre for Agrobiological Research and the Wageningen Agricultural University are currently studying strategies to combine energy saving and optimal control of temperature, carbon dioxide, humidity and light intensity (Bot et al., 1988).

New glasshouse designs and covering materials are being tested, aimed at higher light transmission (i.e. higher production). A glasshouse with a closed roof and forced cooling in which the input of pesticides and energy, and consequently the emission of $\mathrm{CO}_{2}$ and pollutants can be reduced, is being tested in Naaldwijk. Research is focused on the possible use of coated glass withn - in comparison to uncoated glass - at least equal light and lower energy transmission. Environmental effects of use of artificial light (e.g. scattered light) are studied, both in relation to fauna behaviour and human well-being.

Solid waste in glasshouse horticulture, such as substrate material, plastic film and organic material, is being already partly recycled. Research has been started on composting of organic waste.

For soil and non-soil based production systems implications are being studied for optimal choice of materials. Based on the results, management systems are developed to guide decision-making of the growers.

\section{Introduction and evaluation of prototype systems}

The short term environmental aims of the glasshouse sector, as outlined in Table 3, have created a heavy task for research workers, advisors and growers. For the three main issues (nutrients, pesticides and energy) successful introduction of environmentally safe systems in practice can only be reached if a firm-orientated and integrated approach is adopted. This means that prototypes of new systems have to be evaluated and tested continuously in practice. So, research projects as outlined before, have to inlude a testing phase guided by supervising committees of the horticultural industry. Additional guidelines of the government are needed for weighing the 


\section{G.W.H. WELLES}

environmental effects of various systems. Environmental balances for different materials and systems are being evaluated.

Finally, the general concern of the public about the effects of soilless culture on environment, consumers' health and traditional agricultural production, should be anticipated by information on energy and nutrient input/output sheets, quality of products and environmental risks. Studies by Gysi \& Reist (1990) reveal that, with respect to the above-mentioned criteria, intensive soilless production can to be considered more favourable than soil-based intensive production. If consumers are correctly informed, it may stimulate their appreciation of integrated horticultural products, and enable the widespread introduction of these environmentally safer production systems.

\section{Conclusions}

In order to establish a sustainable, safe and competitive glasshouse horticulture, production systems and management have to be improved. Clean production systems are needed not only because of governmental aims, but also because of changing consumer attitudes towards the product quality in relation to the production process. Only advanced integrated production systems with minimim inpunts and emission can fulfil the strict environmental aims. However, also the reluctance of consumers must be overcome to allow the horticultural industry a successful conversion from traditional soil-based systems to integrated (soilless) systems.

\section{References}

Anonymous, 1990. National Environmental Policy Plan of the Netherlands. Ministry of Housing, Physical Planning and Environment. SDU, The Hague, 193 pp.

Anonymous, 1991. Multi Year Crop Protection Plan. Government decision. (In Dutch). Ministry of Agriculture, Nature Management and Fisheries. SDU, The Hague. (Essentials available in English).

Bakker, J.C., \& G.P.A. van Holsteyn, 1989. Horizontal temperature distribution in heated glasshouses: causes and effects. Acta Horticulturae 245: 226-231.

Bot, G.P.A., N.J. Van de Braak, H. Challa \& E.M. Nederhoff, 1988. Working group 'Control of the glasshouse climate in the nineties'. Report of a multi-disciplinary project. Report no 28, $17 \mathrm{pp}$. (In Dutch). Department of Horticulture, Wageningen Agricultural University.

Gysi, Ch. \& A. Reist, 1990. Hors-sol Kulturen - eine okologische Bilanz. Landwirtschaft Schweiz $3(8): 447-459$.

Ramakers, P.M.J., 1989. Simultaneous use of beneficial arthropods for biocontrol of pests and for biopollination in fruiting vegetables. Proceedings, Joint Experts' Meeting on Practical Application of Integrated Control in Protected Crops, Antibes, France, 256 pp.

Rattink, H., 1990. Possibilities of biological control of Fusarium wilt of carnation .Mededelingen Faculteit Landbouwwetenschappen Rijksuniversiteit Gent 54 (26): 517-524.

Rattink, H., 1991. Epidemiology of Fusarium crown and root rot in artificial substrate systems. Mededelingen Faculteit Landbouwwetenschappen Rijksuniversiteit Gent 56/2b: 423-430.

Van de Werken, J., 1991. Development of an unmanned air assisted tunnel sprayer for orchards. $1991 \mathrm{BCPC}$ Mono, no. 46. Air-assisted spraying in crop protection, $7 \mathrm{pp}$.

Vereijken, P., 1992. A methodic way to more sustainable farming systems. Netherlands Journal of Agricultural Science 40: 209-223. 